\title{
Characterization of hibiscus sabdariffa fiber as potential reinforcement for denture acrylic resins
}

Kenneth Nkemdilim Okeke ${ }^{1}$, Stanley Chibuzor Onwubu ${ }^{1}$, Gertrude Chika Iwueke ${ }^{1}$, Innocent Okechi Arukalam ${ }^{2}$

\footnotetext{
${ }^{1}$ Department of Dental Technology, Federal University of Technology, Owerri, Imo, Nigeria.

${ }^{2}$ Department of Polymer and Textile Engineering, Federal University of Technology, Owerri, Imo, Nigeria.

e-mail:ken.okeke@yahoo.com,profstan4christ@yahoo.com,gertchik2002@yahoo.com,innocentarukalam@yahoo.com
}

\section{ABSTRACT}

This study aimed to determine the characteristics of Hibiscus sabdariffa as a fiber-reinforcement material for denture acrylic resins. The Hibiscus sabdariffa fiber was extracted by hot water retting. The fiber was treated at room temperature in aqueous solution of $\mathrm{NaOH}$ for 8 hours at $8 \%$ concentration. Micrometre gauge and Field emission scanning electron microscope (FE-SEM), Archimedes principle, Fourier transform infrared (FTIR) spectroscopy, and Thermogravimetric analyser were used to characterize the diameter, morphology, density, water content and absorption, functional chemical component and thermal behaviour of Hibiscus sabdariffa fiber. In addition, the reinforcing characteristics of Hibiscus sabdariffa fiber was evaluated using denture acrylic resin. The flexural strength was measured in line with ASTM D 790 using Lloyd ${ }^{\mathrm{TM}}$ three $^{-}$ point bending machine. In line with ASTM D 256, the impact strength was measured using Hounsfield ${ }^{\mathrm{TM}}$ charpy tester. The Micrometre gauge and FE-SEM analysis confirmed that diameter of Hibiscus sabdariffa fiber is within the range of other established reinforcing lignocellulosic fibers so also are the density, moisture content and absorption. The FTIR spectroscopy and TGA analysis confirmed the presence of cellulose, hemicellulose and other components in the fiber which were modified by treatment resulting in decreased hydrophilicity of the fibers thereby improving the thermal stability of the fiber. Furthermore, the bond fiber/matrix adhesion was improved which resulted in improve mechanical properties of the composite. The salient features of this study indicated that based on the suitable properties, Hibiscus sabdariffa fiber can be applied to reinforcing denture acrylics. In addition, and potentially, the use of Hibiscus sabdariffa fiber in reinforcement of denture acrylic resins can trigger further economic benefit while ensuring sustainable, green and safer environment.

Keywords: Denture acrylic resin, hibiscus sabdariffa fiber, fiber properties, reinforcement, mechanical properties

\section{INTRODUCTION}

The last few decades have seen the rise in the application of polymers and their reinforcing synthetic fibers across industries such as automotive, sports, construction packaging and biomedical. In the recent times, environmental concerns awareness, depletion of oil resources, have, however, necessitated measures to enhance the environment and ensure clean and green environment [1-3]. Further to these, the synthetic fibers do not only require complex equipment for their handling, they are difficult to recycle and most times pose health challenges. The search for alternatives to these synthetic fibers has therefore attracted further investigation on the suitability of natural fibres as possible alternatives in the reinforcement of polymers [4$6]$.

Natural fibres are classified as animal - silk, wool and hair; mineral - asbestos; or plant - hibiscus sabdariffa, sisal etc. Plant fibers such as hibiscus sabdariffa (H. sabdariffa) are lignocellulosic materials consisting of helically twisted cellulosic materials that are bound together by lignin and hemicellulose matrix. Cellulose being the major component plays a major role in imparting the physical properties of the fibers and their mechanical properties in composites. Hemicellulose is an amorphous poly-saccharides copolymer and has little strength and is responsible for biodegradability of fibers. Lignin acts as binder between the cellulose and hemicellulose, and makes cell wall of the plant to stiffen, though has poor mechanical properties in comparison to cellulose. Plant fibers have been used as reinforcement for materials for a long time before the emergence of synthetic fibers [7]. Unlike synthetic fibers, plant fibres are 
renewable, easily available, biodegradable, and recyclable, have a low cost, low specific gravity/density, enhanced energy recovery, reduced wear to tools and processing equipment, ease of processing, are environmentally friendly and relatively non-toxic. Other advantages include good mechanical properties. These qualities therefore make plant fibres a material of choice as reinforcing material for polymeric materials [2,7-10].

Hibiscus sabdariffa (H. sabdariffa) is an annual plant from the family of malvaceae and are grown mainly in tropical areas [11]. Mainly planted in different parts of the world for the production of its leaves, flowers, seeds and calyx for medicinal purposes and food industries [12-15]. $H$. sabdariffa fibers have been revealed as a material possessing high potential [10], and this has attracted the attention of researchers and academics to explore the possibility of its introduction in reinforcement of polymers [16]. Despite the various advantages, it has been observed that lignocellulosic fibers have setbacks due to their poor wettability and high moisture absorption thereby hindering the hydroxyl groups from reacting with polar matrices and forming an interlock when used as reinforcement materials [2,17]. To ameliorate the setbacks and produce reactive groups and to interlock with polymer matrices, physical and or chemical modification of the fibers surfaces is effected to improve compatibility with the polymer matrix. The modification cleanses and alters the surfaces of fibers, increases the unevenness of the exterior surfaces and either galvanise the hydroxyl groups $(\mathrm{OH})$ or present new moieties that interlock the fibers with the polymer matrices which in turn impart an improvement on the mechanical properties of composites [18]. Different forms of treatment such as mercerisation,

acetylation, benzoylation, silane coupling, graft copolymerisation, permanganate treatment, maleated coupling etc. have been used [19].

$H$. sabdariffa plant obtained from tropical Africa is mostly red in colour. The stems are mostly discarded as agricultural waste after the calyces and fruits are harvested [12]. It is therefore with the mind that this abundant product (agricultural waste) can be turned into very useful product. At present, there is limited evidence on the use of this fiber as reinforcing material for denture base acrylic resins, hence this investigation to see its potential to be used in denture acrylic resins.

\section{MATERIALS AND METHODS}

\subsection{Retting of the fibers}

H. sabdariffa plants used were collected from Hoedspruit, Limpopo Province, South Africa, The stems were thoroughly washed in tap water to remove dirt and sands from the surface of the basts. The fibers were extracted by separating the basts from the woody part manually and transferring same to the laboratory where further procedures and analysis were done. Retting of the fibers followed the cutting of the separated basts into smaller sizes $(10 \mathrm{~cm})$ to enable entry into laboratory beakers and boiling same in water for three (3) hours, to remove ligneous matters by converting them to soluble products and loosening the fibers for ease of extraction. The fibres were washed in overflowing tap water. The fibers were subsequently scoured in $2 \%$ solution of hydrogen peroxide $\left(\mathrm{H}_{2} \mathrm{O}_{2}\right)$ by boiling for 45 minutes to remove impurities, pectin, waxes, gum fats and oils from the fiber surfaces, and to improve the colour. Afterwards, they were rinsed under tap water severally to eliminate the traces of $\mathrm{H}_{2} \mathrm{O}_{2}$ and then air dried at room temperature for 24 hours (Figure 1), and subsequently at $70^{\circ} \mathrm{C}$ for 24 hours. 


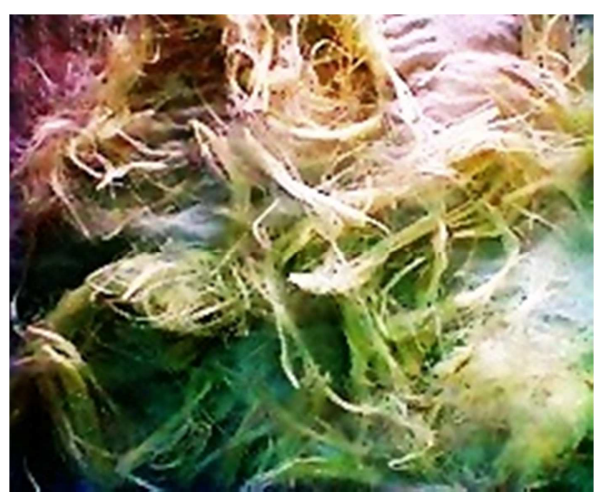

Figure 1: Retted H. sabdariffa fibers

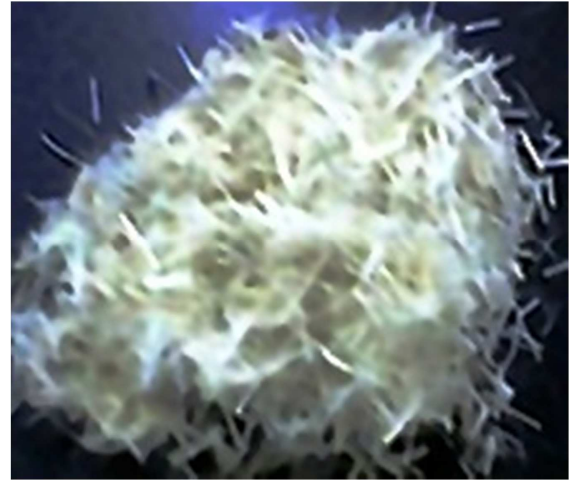

Figure 2: 6mm fibers

\section{2 Mercerization of the fibers}

The fibers were soaked in $8 \%$ aqueous solution of sodium hydroxide $(\mathrm{NaOH})$ for 8 hours at room temperature. Then the fibers were thoroughly rinsed several times with distilled water to remove traces of the alkali solution and dried at room temperature for 24 hours. Further drying was effected in hot air oven at $70^{\circ} \mathrm{C}$ for 24 hours.

\subsection{Characterisation}

Understanding the properties of $H$. sabdariffa fibers is an important factor in understanding the capabilities and possibilities of the fibre to effect improvement on the mechanical properties of polymeric materials. The characteristics under evaluation include: fiber morphology and cross section, fiber diameter, fiber density, moisture content, water absorption behaviour, chemical/functional groups, and thermal analysis.

\subsubsection{Morphology and Cross section}

The surface morphology and cross section of the untreated and treated $H$. sabdariffa fibers were evaluated under a field emission scanning electron microscope (FE-SEM, Ultra Series ${ }^{\circledR}$ Carl Zeiss, GmbH). The FESEM operated under controlled atmospheric condition. The fibres were sputter coated with gold to ensure good conductivity before the microscopic examination was carried out.

\subsubsection{Fiber Diameter}

The diameter of the untreated and treated $H$. sabdariffa fibers were measured at three different points of the lengths using micrometre (Mitutoyo brand) gauge. 120 samples of fiber were measured and average result reported. Further confirmation of the diameter was done using FE-SEM, Ultra Series ${ }^{\circledR}$ Carl Zeiss, GmbH). The FE-SEM operated under controlled atmospheric condition. The fibres were sputter coated with gold to ensure good conductivity before the microscopic examination was carried out.

\subsubsection{Fiber Density}

The density of the fibres was determined in line with ASTM D792 by applying equation 1 below. In this method based on Archimedes, the weight of the container was determined $\left(M_{1}\right)$, and then immersed in specific volume of water in a calibrated transparent measuring glass tube. The volume of water displaced was determined $\left(\mathrm{V}_{1}\right)$. The container was filled with ground $H$. sabdariffa fibers and the weight determined $\left(\mathrm{M}_{2}\right)$. The fibres filled container was immersed in same known volume of water in same calibrated transparent measuring glass tube. The volume of water displaced was determined $\left(\mathrm{V}_{2}\right)$.

$$
\text { Density }=\frac{\text { Mass }(M 2-M 1)}{\text { Volume displaced }} \quad \text { in } \mathrm{gm} / \mathrm{cm}^{3}
$$




\subsubsection{Moisture Content}

The percentage of moisture content of the fibers was determined by using equation 2 below. The samples were prepared in replicate of five and the average value recorded. The samples were weighed using a digital balance (Adam ${ }^{\circledR}$ Equipment S. A. (Pty) Johannesburg, South Africa) with a capacity to read $0.001 \mathrm{~g}$ and recorded $\left(\mathrm{M}_{1}\right)$. They were placed in an oven at $100^{\circ} \mathrm{C}$ for 24 hours. At the end of the 24 hours, the samples were removed, weighed and recorded. The samples were replaced in the oven and were subsequently weighed at intervals of two hours until no further change was noticed and the final weight recorded $\left(\mathrm{M}_{2}\right)$.

$$
\text { Moisture content }=\frac{M 1-M 2}{M 1} \times 100 \quad \text { in } \%
$$

\subsubsection{Water absorption}

The determination of the percentage of water absorption was done in line with ASTM 570 using equation 3 below. The samples were prepared in replicate of five and the average value recorded. The samples were weighed using a digital balance (Adam ${ }^{\circledR}$ Equipment S. A. (Pty) Johannesburg, South Africa) with a capacity to read $0.001 \mathrm{~g}$ and recorded $\left(\mathrm{M}_{1}\right)$. They were completely submerged in distilled water in a beaker at room temperature for 24 hours. At the end of the 24 hours, the samples were removed, drained of excess water and weighed within 60 seconds from removal of fibre from water $\left(\mathrm{M}_{2}\right)$.

$$
\text { Water absorption }=\frac{\mathrm{M} 2-\mathrm{M} 1}{\mathrm{M} 1} \quad \mathrm{x} 100 \text { in } \%
$$

\subsubsection{Functional/Chemical Groups (FT-IR analysis)}

The Fourier transform infrared spectroscopy (FTIR) of untreated and treated H. sabdariffa fibers was recorded using Perkin Elmer Universal spectrometer in the frequency of $4000 \mathrm{~cm}^{-1}$ to $380 \mathrm{~cm}^{-1}$, operating in attenuated total reflectance (ATR) mode.

\subsubsection{Thermal Analysis}

The samples of untreated and treated $H$. sabdariffa fibers were cut into small pieces and thermogravimetric analysis (TGA) carried out. The thermograms were recorded on SDT Q600 series (TA Instruments,

Delaware, USA) under dry nitrogen gas flow at the rate of $100 \mathrm{ml} / \mathrm{min}$ between temperature range $20^{\circ} \mathrm{C}$ to $600^{\circ} \mathrm{C}$

\subsection{Processing of Denture acrylic resin composite}

The treated fibers were chopped into $6 \mathrm{~mm}$ length (Figure 2) with the aid of scissors. Heat-cure acrylic resin (Vertex ${ }^{\mathrm{TM}}$ Rapid Simplified, Vertex Dental, BV, The Netherlands) was used in this study. Two groups of specimens (unreinforced and treated fiber-reinforced) were fabricated. Mixing and Processing of the materials followed manufacturer's guidelines. Although the guidelines recommended using a mixing ratio of $0.33 \mathrm{ml}$ of monomer to $1 \mathrm{gm}$ of powder, this ratio was adjusted from $0.60 \mathrm{ml}$ of monomer to $1 \mathrm{gm}$ of powder for the fiber-reinforced specimens only. This was to ensure complete wetting of the fibers within the mix.

The pre-determined fiber weight percentage $(2.5 \mathrm{wt} \%)$ was soaked in appropriate quantity of monomer in a mixing closed vessel for 10 minutes. This wetting of the fibers facilitates better adhesion of the fibers and the acrylic resin. Appropriate quantity of powder was mixed with the monomer containing the fibers and thoroughly stirred to ensure random distribution of the fibers and a homogenous mix. A total of 20 specimens (10 unreinforced and 10 fiber-reinforced). The specimens were divided into two groups of 10 each for flexural and impact testing (Table 1). 
Table 1: Summary of tests and sample groups.

\begin{tabular}{l|l|c}
\hline \multirow{2}{*}{ TESTS } & $\begin{array}{c}\text { SAMPLE } \\
\text { GROUPS }\end{array}$ & $\begin{array}{c}\text { NUMBER } \\
\text { OF } \\
\text { SPECIMENS }\end{array}$ \\
\hline $\begin{array}{l}\text { Flexural } \\
\text { strength }\end{array}$ & Unreinforced & 5 \\
\cline { 2 - 3 } & Reinforced & 5 \\
\hline \multirow{2}{*}{ Impact } & Unreinforced & 5 \\
\cline { 2 - 3 } & Reinforced & 5 \\
\hline
\end{tabular}

Specimens with dimensions measuring $60 \mathrm{~mm} \times 10 \mathrm{~mm} \times 3 \mathrm{~mm}$ (length, width and thickness respectively) for flexural test, and $50 \mathrm{~mm} \times 10 \mathrm{~mm} \times 3 \mathrm{~mm}$ (length, width and thickness respectively) for impact test were fabricated in line with ISO 1567: 1999 (ADA specification No. 12). The specimens were trimmed using a tungsten carbide bur and smoothened using silicon carbide abrasive paper. The dimensions of specimens were maintained post trimming and finishing. Specimens for impact test only were prepared with $2 \mathrm{~mm}$ v-notch at the center. The specimens were stored in distilled water at $37^{\circ} \mathrm{C}$ for 72 hours prior to testing. Following the ASTM D 790 method, a three point bending test on a Lloyd ${ }^{\mathrm{TM}}$ LR $30 \mathrm{~K}$ machine (Lloyd Instruments Ltd; West Sussex, UK) was carried out to test the flexural strength of specimens. The distance between the jig supports was $50 \mathrm{~mm}$. The machine was set to provide at a cross head speed of $5 \mathrm{~mm} / \mathrm{min}$ and the force applied was located at the center of the specimen until fracture occurred. The maximum force applied was recorded by the computer software attached to the machine. The data obtained was used to calculate the flexural strength using the equation 4 below, and the average values reported.

$$
\text { Flexural strength }=3 F L / 2 B H^{2} \quad(\mathrm{MPa})
$$

Where $\mathrm{F}=$ maximum force $(\mathrm{N})$ at fracture, $\mathrm{L}=$ distance between supports $(\mathrm{mm})$

$\mathrm{B}=$ width of specimen $(\mathrm{mm}), \mathrm{H}=$ height or thickness of specimen $(\mathrm{mm})$

Similarly, following the ASTM D 256 method, a Hournsfield ${ }^{\mathrm{TM}}$ charpy tester (Tensometer Ltd; Croydon, England) was used for impact testing. Using equation 5, the impact strength was calculated and average values reported.

$$
\text { Impact strength }=A E / T W \quad \mathrm{X} \quad 10^{3} \quad\left(\mathrm{KJ} / \mathrm{M}^{2}\right)
$$

Where $\mathrm{AE}=$ absorbed energy, $\mathrm{T}=$ thickness of specimen $(\mathrm{mm})$

$\mathrm{W}=$ remaining width of specimen at the notch area $(\mathrm{mm})$

\section{RESULTS AND DISCUSSION}

Properties of lignocellulosic fibers are part of the major influencing factors in reinforcement of polymers. When mercerisation is effected on lignocellulosic fibers, modification occurs through the breaking down of hydrogen bonds in the network structure thereby enabling effective interfacial adhesion between the fibres and the matrices [20]. The reaction between the fibre and the alkali material is shown thus: 
Fiber- $\mathrm{OH}+\mathrm{NaOH} \longrightarrow$ Fiber $\mathrm{O}-\mathrm{Na}^{+}+\mathrm{H}_{2} \mathrm{O}+$ surface impurities.

\subsection{Morphology and Cross section}

Figures 3 (A) and (B) present the FE-SEM micrographs of the untreated and treated $H$. sabdariffa fibers, respectively. The untreated fibers (A) show structural network of bundles of fibers held together by lignin, wax and hemicellulose. Impurities and debris are present on the smooth surface layer of the fibers. On the treated fibres (B), the micrograph shows a clean yet rough fiber surfaces. This is because treatment removes hemicellulose, wax, oil, impurities and debris from the fiber surfaces; roughens and makes the fiber surfaces uneven. This rough surfaces indicates increased amount of cellulose exposed and ready to promote interfacial bonding between the fibers and polymer matrices during reinforcement [21].

As seen in Figure 4 (A) the untreated fibers are bundled together by non-fibrous materials and hollow structure (lumen) within the H. sabdariffa fibers. In contrast, the treated fibers (Figure 4(B)) presents a narrower lumen which indicates the removal of wax, oil, surface impurities and debris from the surfaces of the fibers. This reduction in lumen size reduces the diameter of the fibers which ultimately increases the aspect ratio of the fibers and enhanced packing of the cellulose chains [22-24].

Table 2: Physical properties of tested H. sabdariffa fibers

\begin{tabular}{c|c|c|c|c}
\hline $\begin{array}{c}\boldsymbol{H} . \\
\text { SABDARIFFA } \\
\text { FIBERS }\end{array}$ & $\begin{array}{c}\text { FIBER } \\
\text { DIAMETER } \\
(\boldsymbol{\mu M})\end{array}$ & $\begin{array}{c}\text { FIBER } \\
\text { DENSITY } \\
\left(\mathbf{G} / \mathbf{C M}^{3}\right)\end{array}$ & $\begin{array}{c}\text { MOISTURE } \\
\text { CONTENT } \\
(\%)\end{array}$ & $\begin{array}{c}\text { MOISTURE } \\
\text { ABSORPTION } \\
(\%)\end{array}$ \\
\hline Untreated & $40-90$ & 1.38 & 9.8 & 169 \\
\hline Treated & $30-73$ & 1.43 & 7.8 & 109 \\
\hline
\end{tabular}
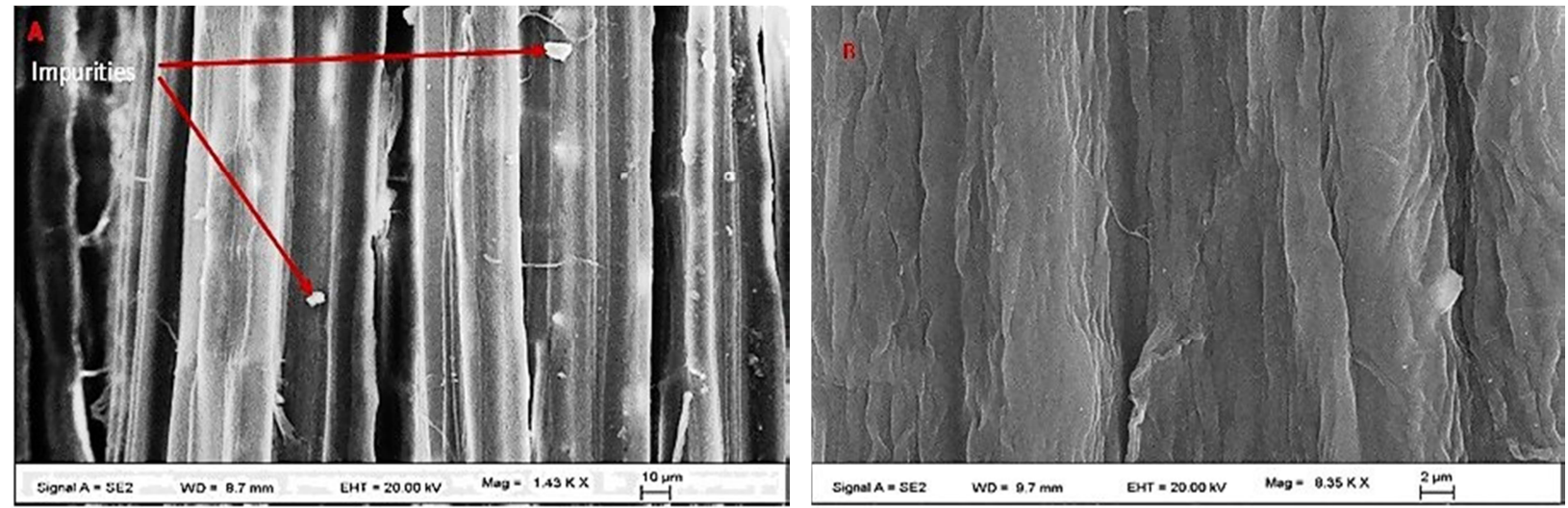

Figure 3: Surface morphology of $H$. sabdariffa fibers: (A) untreated; (B) treated. 

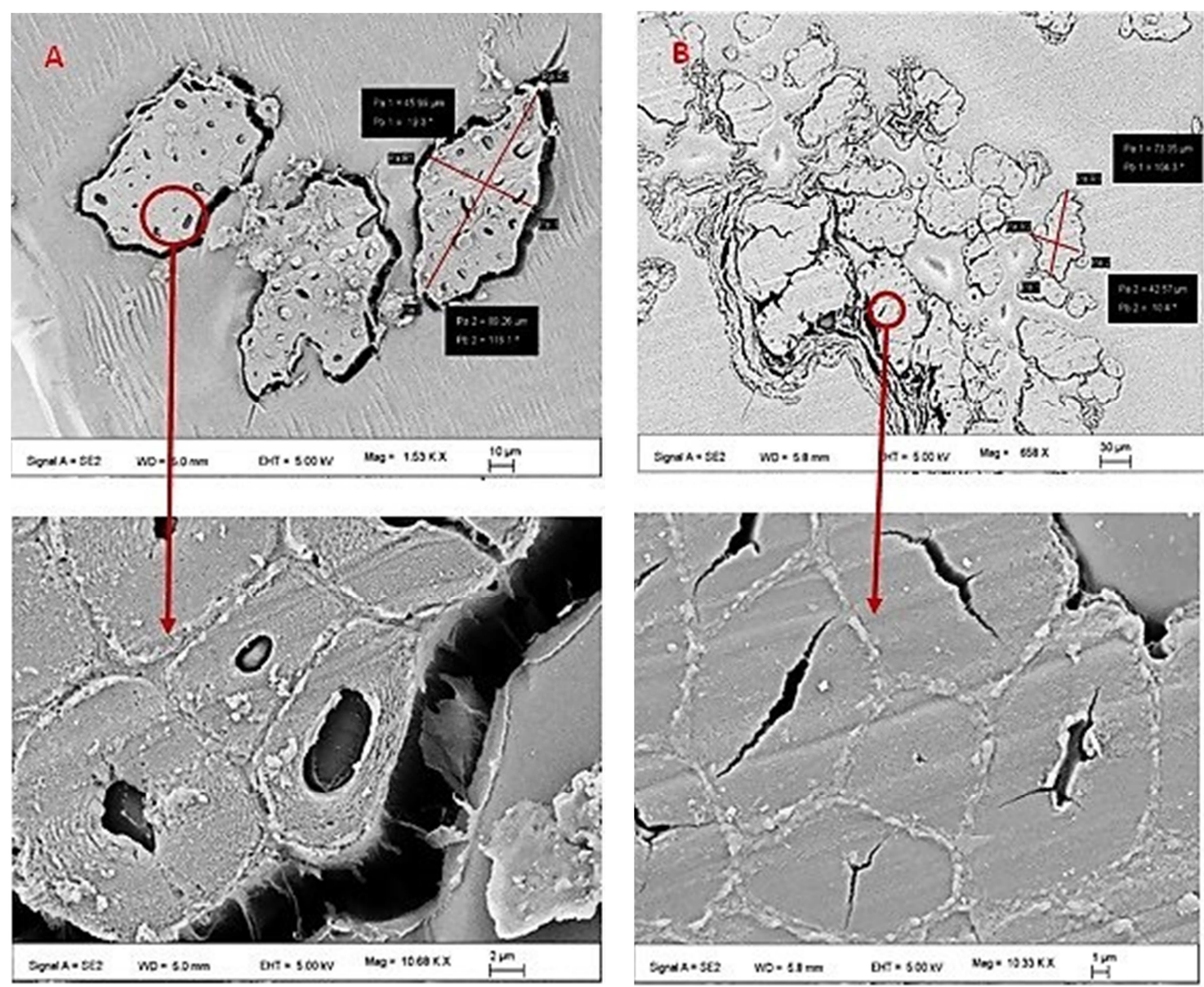

Figure 4: Cross section and Diameter of $H$. sabdariffa fibers: (A) untreated; (B) treated

\subsection{Fibre Diameter}

As shown in Table 2 and Figure 4, the diameter range of the untreated and treated $H$. sabdariffa fibers ranges from $40 \mu \mathrm{m}$ to $90 \mu \mathrm{m}$ and $30 \mu \mathrm{m}$ to $73 \mu \mathrm{m}$, respectively. The decrease in the diameter of the treated fibers could have been caused by the removal of hemicellulose from the fiber surfaces thereby leading to the shrinkage of the lumen and invariably increase in aspect ratio of the fibers. The variation in the diameter of the fibers may be due to bundles of fibers being inconsistent in size. Technically, a single fiber consists of bundle of fibers and it is difficult to get individual fibers measurement with the bare eyes [25]. This difficulty results from inconsistency in the physical properties of lignocellulosic fibers [21]. It can be observed that getting a particular diameter for $H$. sabdariffa fibers is difficult as each fiber sample presents different measurements at different spots within each fiber length. This finding is consistent with the work of several authors $[4,16,22]$, where diameter of $H$. sabdariffa fibers was reported to be between 40 to $150 \mu \mathrm{m}$.

Variation in physical properties of lignocellulosic fibers can be attributed to location, source of plant, age, part of the plant, environmental condition, extraction technique, fibers microstructure, testing and characterization techniques [23-24]. These factors are considered responsible for the variation and nonuniformity of diameters of natural fibers [26]. Fibre diameter is an important factor in considering reinforcement with lignocellulosic fibers as aspect ratio of fiber (length/diameter) is a critical factor in reinforcement of polymers. A very low aspect ratio weakens composites while mid and high aspect ratio improves the mechanical properties of composites [27]. From the above result, it shows that composite reinforced with this treated fibers is most likely to show an improved properties considering the high aspect ratio.

\subsection{Fiber density}

As presented in table 2, the density of untreated and treated $H$. sabdariffa fibers are $1.38 \mathrm{~g} / \mathrm{cm}^{3}$ and $1.43 \mathrm{~g} / \mathrm{cm}^{3}$, respectively. From the results, it is clear that mercerisation which removed the wax, oil and other 
deposits from the fibers surface caused it to densify. The results further indicate that the density of the fiber is relatively low and corresponds with advantage of natural fibers. Low density is responsible for the light weight of natural fibers and invariably reinforcements. The low density of the fiber is due the presence of lumen (hollow structure) in the fibre. This lumen is responsible for the lightness of lignocellulosic fibers [28]. This lightness of $H$. sabdariffa fibers is a necessary factor in the reinforcement of polymeric materials. Though fibre density changes with the maturity of the plant, $H$. sabdariffa fiber has shown maximum density when the plant is about 6 months old [29]. The result obtained in this study is consistent with several other literature $[4,16,25,30]$, and that composite reinforced with $H$. sabdariffa fiber will not be negatively affected in terms of weight.

\subsection{Moisture content}

The moisture content averaged $9.8 \%$ and $7.8 \%$ for untreated and treated $H$. sabdariffa fibers, respectively corresponding to $20.4 \%$ reduction. This confirms that hemicellulose, which is responsible for water storage in lignocellulosic fibers were removed by the treatment. The moisture content of lignocellulosic fibers affect the volumetric change in composites which in turn leads to internal stress in the composite and ultimately weakens mechanical properties [31]. Moisture content and absorption are closely related and affect the mechanical properties of composites [7]. Similarly, water absorption and mechanical properties of composites are dependent on the water content and the degree of retting of the fibers with the hemicellulose content being responsible for water storage in lignocellulosic fibers [31]. Fibers with low percentage of hemicellulose have low water content, and are more likely to perform better with more service life in reinforcements than fibers with high water content [7]. The result of this study indicated that $H$. sabdariffa fibers compares favourably with properties of other established lignocellulosic fibers [34-40], and that mercerization removed the hemicellulose hence decreased the water content of the $H$. sabdariffa fiber.

\subsection{Moisture absorption}

The moisture absorption of is the percentage of water dry fibers can absorb from the air under standard temperature and pressure at $25^{\circ} \mathrm{C}$ and $65 \%$ humidity. The untreated and treated $H$. sabdariffa fibers had a moisture absorption of $169 \%$ and $109 \%$ respectively. This high moisture absorption rate of untreated fibers can be attributed to the high rate of lumen and large amount of hydroxyl group within the cell walls of the fibers. Water absorption by natural fibers could induces volumetric alteration in composites which can lead to internal stress and ultimately weaken the composite [31]. In contrast to the untreated fibers, there was a reduction in the moisture absorption rate of treated fibers. This could be attributed to the removal of hemicellulose, wax and oily substances from the surface through mercerisation which caused the cellulose to collapse and glue together. Though variability of properties of lignocellulosic fibers has been one of the challenges in predicting the properties of lignocellulosic fibers and their composites [32]. The rate of water absorption by lignocellulosic fibers is dependent on composition, dimensions, surface area, and hydrophilicity of the components, surface protection and exposure time of the fibers, hence there is a direct correlation between moisture absorption and mechanical properties of composites [33].

Moisture content and absorption by lignocellulosic fibers are important factors to be considered in making composites. This is because moisture can act as plasticiser in composites thereby reducing the mechanical properties [32]. Moisture absorption behaviour of lignocellulosic fibers must therefore be reduced through surface modification of the fibers in order to ensure the production of composites with good mechanical properties. Surface modification of fibres facilitates efficient hydrophobic barrier and wettability properties, thus making cellulose available for composite formation, and ultimately help good fiber/polymer bonding [18]. Strong bonding decreases moisture absorption in composites.

\subsection{Chemical Functional groups (FT-IR)}

The functional chemical structure of the components of untreated and treated $H$. sabdariffa fibers were studied using FT-IR (ATR) and the spectra presented in Figure 5(A) and (B), respectively. The spectra showed typical transmittance bands which correspond with components of lignocellulosic corresponding to cellulose, hemicellulose and lignin. In contrast to the untreated fibers, the spectrum in Figure 5(B) showed a prominent peak at $3328 \mathrm{~cm}^{-1}$ which is associated with hydrogen bonded $\mathrm{O}-\mathrm{H}$ stretching of cellulose.

Hydroxyl based materials are usually detected in the region of $3400 \mathrm{~cm}^{-1}$ to $3300 \mathrm{~cm}^{-1}$. The peak at 2901 and 1598 could be attributed to $\mathrm{C}-\mathrm{H}$ stretching bend of cellulose and $\mathrm{C}=\mathrm{C}$ stretching of the aromatic ring of lignin, respectively [22, 41-44]. The peak observed at $1421 \mathrm{~cm}^{-1}$ can be ascribed to $\mathrm{CH}$ stretching 
while the $1368 \mathrm{~cm}^{-1}$ can be associated with $\mathrm{C}-\mathrm{H}$ bending stretch of cellulose. In addition, the transmission peaks of $1157 \mathrm{~cm}^{-1}$ and $1027 \mathrm{~cm}^{-1}$ can be linked with asymmetric stretching of C-O-C of lignin and C-O stretching of polysaccharides in cellulose, respectively $[22,42,43]$. The peak observed at $895 \mathrm{~cm}^{-1}$ could be linked with the presence of $\beta$ glycosidic linkages between monosaccharides of cellulose. The peaks occurring at $657 \mathrm{~cm}^{-1}$ and $554 \mathrm{~cm}^{-1}$ can be associated with the out of plane vibrations of ring structure and COH stretching $[26,43]$.
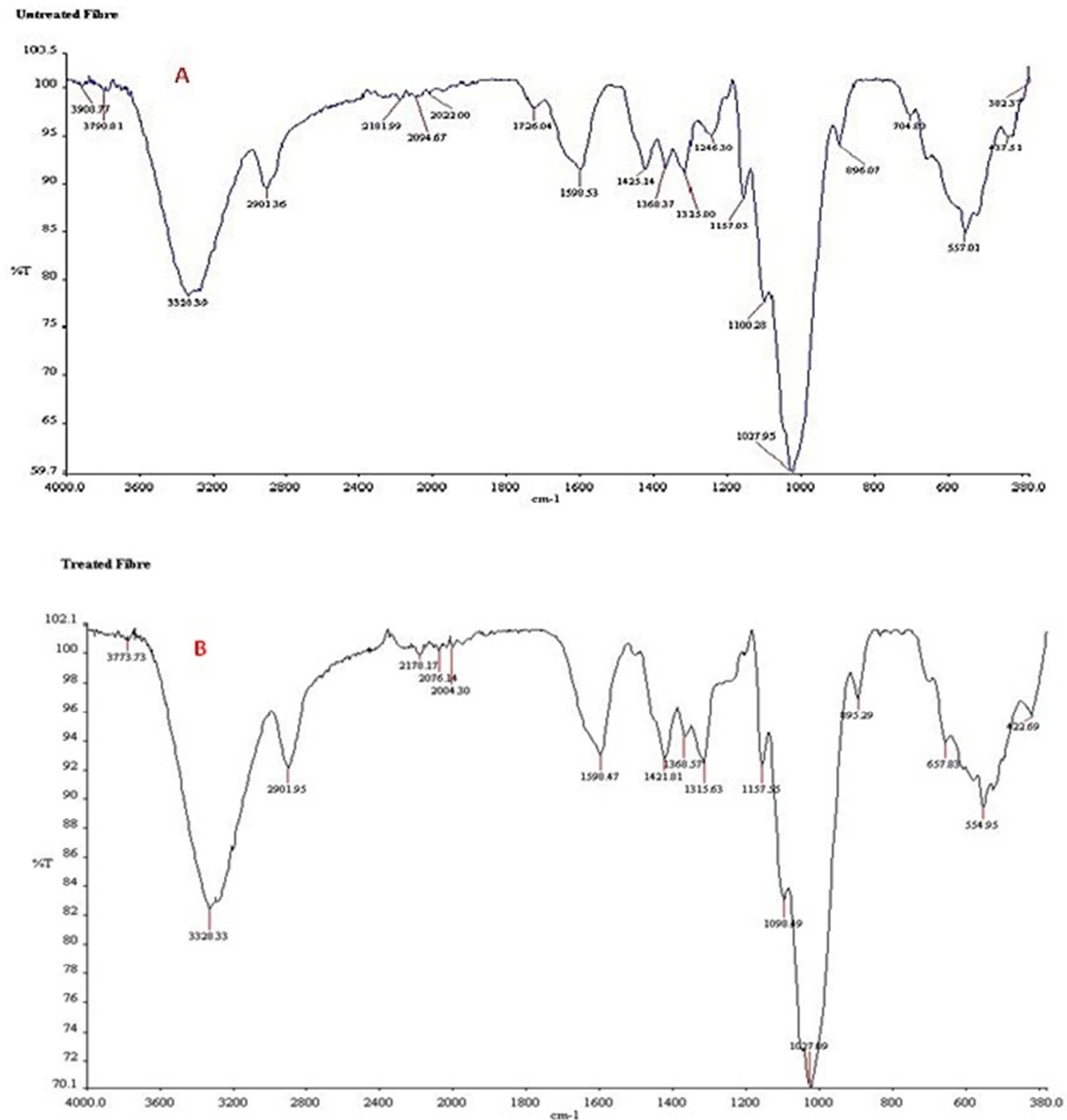

Figure 5: FT-IR (ATR) spectra of H. sabdariffa fibers: (A) untreated; (B) treated

Unlike the shift of the peaks $2178 \mathrm{~cm}^{-1}$ to $2004 \mathrm{~cm}^{-1}$ and $1421 \mathrm{~cm}^{-1}\left[2181 \mathrm{~cm}^{-1}\right.$ to $2022 \mathrm{~cm}^{-1}$ and $1425 \mathrm{~cm}^{-1}$ in Figure 5(A), there was a disappearance of $\mathrm{C}=\mathrm{O}$ stretching peak of hemicellulose at $1726 \mathrm{~cm}^{-1}$ and a decrease in the intensity of the peak at $1246 \mathrm{~cm}^{-1}$ in treated fibres. This confirmed that mercerisation significantly removed hemicellulose. Moreover, the intensity of the transmittance peak of $3328 \mathrm{~cm}^{-1}$, the elimination of peak $3908 \mathrm{~cm}^{-1}$ and the shift in the peak of $3790 \mathrm{~cm}^{-1}$ indicate that the cellulose structure changed. This correlates to the work of several authors [22, 41-42, 46-47], particularly with regards to mercerization removing non-cellulosic materials while changing the structure of cellulose. It can therefore be inferred from the FT-IR results that the $\mathrm{OH}$ groups of the mercerized $H$. sabdariffa fibers were activated to release active group for better interfacial bonding with the polymer matrix. 


\subsection{Thermogravimetric Analysis (TGA)}

In contrast to Figure 6(A), the TGA curves in Figure 6(B) present two thermal events within the temperature range of $40^{\circ} \mathrm{C}$ to $800^{\circ} \mathrm{C}$. The first thermal event at $42^{\circ} \mathrm{C}$ can be attributed to the evaporation of moisture and volatile extractives from the fibers. Consequently, there was a weight loss of about $6.9 \%$, which could be attributed to the reduction of free hydroxyl groups from the fibers. The final thermal degradation noticed between $300^{\circ} \mathrm{C}$ to $400^{\circ} \mathrm{C}$ was the decomposition of cellulose. This compares with the work of [44], that the thermal stability of fibers improved due to mercerization. Significantly, Figure 6(B) confirms that mercerization reduced the hemicellulose content, which accounts for the low water content of the $H$. sabdariffa fibers. The char content of $28.9 \%$ further supports the reduction of hemicellulose and water [22, 41]. Ultimately, this increased the final degradation temperature, which effectively improved the thermal stability of the treated fibers. The water content results in Table 3-2 further support this assertion.
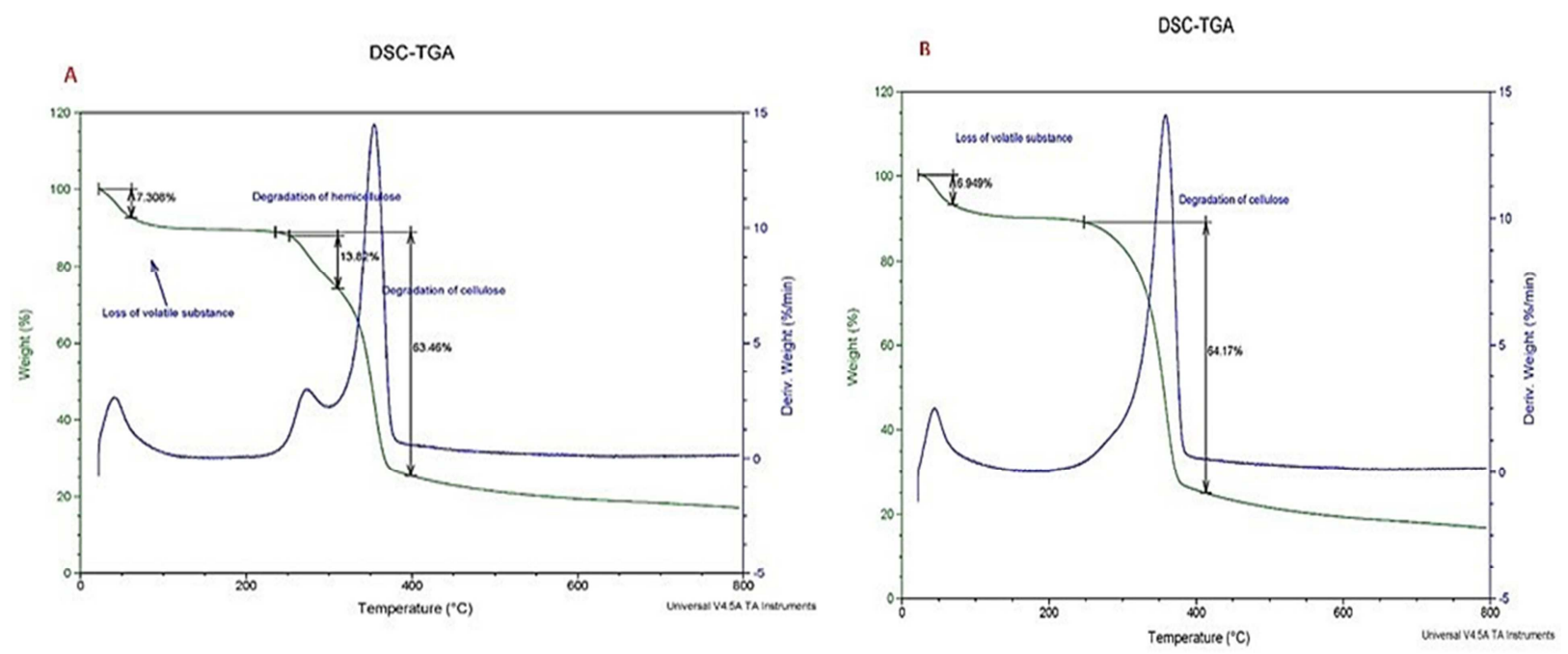

Figure 6: TGA curves of $H$. sabdariffa fibers: (A) untreated; (B) treated.

\subsection{Mechanical properties of composite}

The results of the flexural and impact strengths of denture acrylic resin and the composite are highlighted in Table 3 and Figure 7. In contrast to the denture acrylic resin, the flexural and impact strengths of the composite was found to increase with the reinforcement. From the results, the $H$. sabdariffa fiber-reinforced specimens showed a flexural strength of $92.64 \mathrm{MPa}$ as against $83.55 \mathrm{MPa}$ of the unreinforced denture acrylic resin. This is about $10.88 \%$ increase. Similarly, the impact strength showed the unreinforced $\left(14.12 \mathrm{KJ} / \mathrm{M}^{2}\right)$ and fiber-reinforced $\left(15.05 \mathrm{KJ} / \mathrm{M}^{2}\right)$, about $6.58 \%$ increase.

These increase could be attributed to the restrain imposed by the incorporation of fibers to the formation, propagation of cracks and failure of denture acrylic resin. The pre-soaking of the fibers in the monomer may have resulted in better wetting of the fibers and enhanced interfacial attraction between the $H$. sabdariffa fibers and the PMMA matrix, and the reinforcing effect of the fibers through stress transfer from the matrix to the fibers [48-50].

Furthermore, and as indicated in Table 2, the treatment of the fibers led to reduction in diameter of the fibers which may have improved the aspect ratio and more surface area for interaction between the fibers and denture acrylic resin hence, improved mechanical properties [18]. Also, mercerization treatment have eliminated hemicellulose and impurities from the fiber thereby roughening the surfaces, as seen in Figure 3 (B), exposing more reactive -OH group for better bonding with hydrophobic polymer [44,47]. This is further confirmed from the FTIR spectra (Figure $5(\mathrm{~B})$ ) with the disappearance of $\mathrm{C}=\mathrm{O}$ peak at $1726 \mathrm{~cm}^{-1}$ and the decrease in intensity of peak $1246 \mathrm{~cm}^{-1}[22,46]$. Similarly, the TGA curve in Figure 6 (B) showed increased char content of the treated fiber further confirming the elimination of hemicellulose content of the fibers hence the acrylic composite is most likely to be thermally stable. 
Table 3: Mechanical properties of tested specimens

\begin{tabular}{c|c|c}
\hline TESTS & SAMPLE GROUP & VALUE \\
\hline \multirow{2}{*}{$\begin{array}{c}\text { Flexural } \\
\text { strength }\end{array}$} & Unreinforced & $83.55 \mathrm{MPa}$ \\
\cline { 2 - 3 } & Reinforced & $92.64 \mathrm{MPa}$ \\
\hline \multirow{2}{*}{$\begin{array}{c}\text { Impact } \\
\text { strength }\end{array}$} & Unreinforced & $14.12 \mathrm{KJ} / \mathrm{M}^{2}$ \\
\cline { 2 - 3 } & reinforced & $15.05 \mathrm{KJ} / \mathrm{M}^{2}$ \\
\hline
\end{tabular}

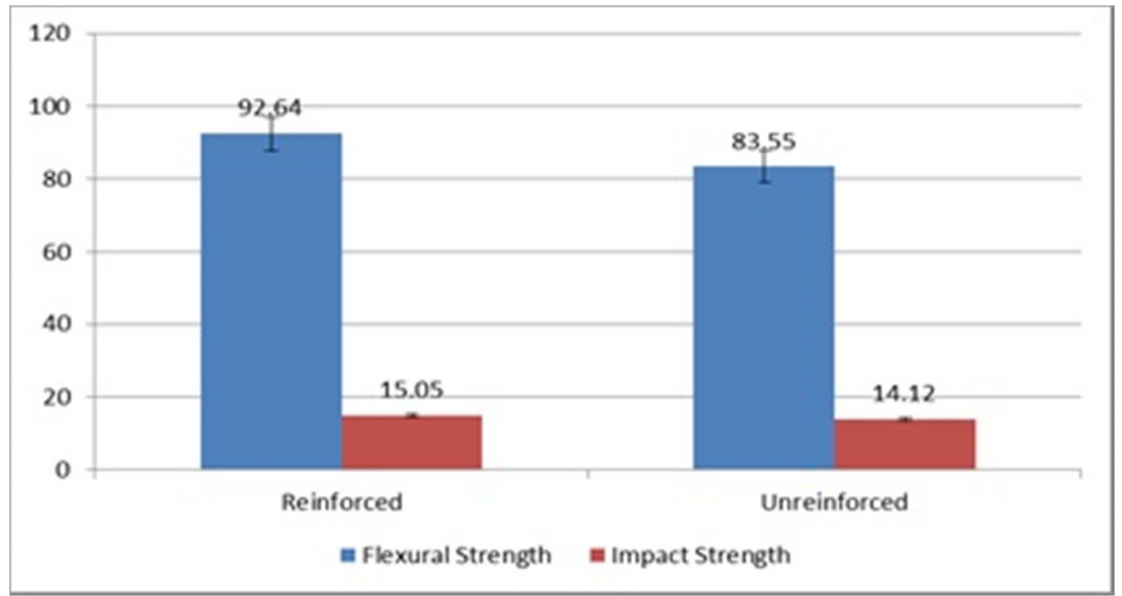

Figure 7: Mean Flexural and impact strengths of unreinforced and reinforced acrylic resins.

While lignocellulosic fibers are known to have high moisture absorption capacity, the effect of mercerisation treatment has indicated the removal of non-cellulosic components from the $H$. sabdariffa fibers leading to reduction in the hydrophilic nature of the fibers making them most likely not to absorb much water as the water retaining portion was removed by the treatment. Therefore, it can be inferred that mercerized $H$. sabdariffa fibers-reinforced acrylic resin will not be adversely affected by moisture absorption and invariably the quality of composite maintained. Strength property being one of the critical factors in determining the success of dentures intra-orally, therefore improving this strength property using H. sabdariffa fibers will ensure longer lasting dentures.

\section{CONCLUSIONS}

The $H$. sabdariffa fibers were extracted from the bast of the stem by hot water retting process. Mercerisation of the fibers resulted in the solubilisation of hemicellulose component and consequent reduction in the fibers. Similarly, the removal of surface impurities from the fibers led to the alteration of the surface topography, activation of the hydroxyl groups which when in contact with polymeric materials facilitate interfacial bonding. FT-IR offered additional information on the activation of the reactive groups. The mercerization initiated the transformation of amorphous cellulose to crystalline cellulose. Mercerization caused the reduction in the size of the lumen leading to corresponding reduction in the fiber diameter and invariably increase in the aspect ratio as well as densification of the fibers.

The result further indicated that mercerised H. sabdariffa fibers contained and also absorbed less moisture than the untreated fibres. The TGA analysis showed that thermal stability of mercerised fibres improved considerably with an enhanced char formation in comparison to the untreated fibres. It was therefore established that $H$. sabdariffa fibers having characteristics comparable to some established reinforcing lignocellulosic fibers show potentials as reinforcement in polymeric materials. Mercerized $H$. sabdariffa fiber was successfully used in reinforcing denture acrylic resin. Acrylic resin composite reinforced with $H$. sabdariffa fiber showed improved mechanical properties and can therefore be extended to 
other biomedical applications. The success can usher in a source of economic development in value chain of H. sabdariffa fibers with systematic and sustained clean, green and safer environment.

\section{BIBLIOGRAPHY}

[1] ALIREZ, A., "Wood-plastic composites as promising green composites for automotive industries", Bioresource Technology, v. 99, n. 11, pp. 4661-4667, 2008.

[2] TAJ, S., MUNAWAR, M. A., KHAN, S., "Review: natural fiber-reinforced polymer composites", Proceedings of Pakistan Academy of Sciences, v. 44, n. 2, pp. 129-144, 2007.

[3] MOHANTY, A. K., MISRA, M., DRZAL, L. T., "Sustainable biocomposites from renewable resources: opportunities and challenges in the green materials world", Journal of Polymers and the Environment, v. 10, n. 1/2, pp. 19-26, 2002.

[4] NADLENE, R., SAPUAN, S. M., JAWAID, M., et al., "Material characterisation of roselle fiber (Hibiscus sabdariffa L.) as potential reinforcement material for polymer composites", Fibers and Textiles in Eastern Europe, v. 23, n. 6, pp. 23-30, 2015.

[5] DAS, G., BISWAS, S., "Physical, mechanical and water absorption behaviour of coir fiber -reinforced epoxy composites filled with $\mathrm{Al}_{2} \mathrm{O}_{3}$ particles", IOP Conference series: Materials Science and Engineering, 115, 2016.

[6] SINGHA, A. S., THAKUR, V. K., "Fabrication of hibiscus sabdariffa fiber reinforced polymer composite", Iranian Polymer Journal, v.17, n.7, pp. 541-553, 2008.

[7] JAWIAD, M., ABDUL KHALIL, H. P. S., "Cellulose/synthetic fiber reinforced polymer hybrid composites: a review", Carbohydrate Polymers, 85, pp. 1-18, 2011.

[8] GEORGOPOUlOS, S. T., TARANTILI, P. A., AVGERINOS, E., et al., "Thermoplastic polymers reinforced with fibrous agricultural residues". Polymer Degradation Stability, v. 90, pp. 303-312, 2005.

[9] SINGHA, A. S., THAKUR, V. K., "Effect of fiber loading on urea formaldehyde matrix based green composites", Iranian Polymer Journal, v. 17, n. 11, pp. 861-873, 2008.

[10] CHANDRAMOHAN, D., BHARANICHANDAR, J., "Impact test on natural fiber reinforced polymer composite materials", Carbon-Science and Technology, v. 5, n. 3, pp. 314-320, 2013.

[11] MAHADEVAN, N., KAMBOJ, S., KAMBOJ, P., "Hibiscus sabdariffa linn.- an overview", Natural Product Reliance, v. 8, n. 1, pp. 77-83, 2009.

[12] PATEL, S., "Hibiscus sabdariffa: an ideal yet under-exploited candidate for nutraceutical applications", Biomedicine and Preventive Nutrition, 4, pp. 23-27, 2014.

[13] McKAY, D. L., CHEN, C-Y. O., SALTZIMAN, E., et al., "Hibiscus sabdariffa L. tea (tisane) lowers blood pressure in prehypertensive and mildly hypertensive adults". Journal of Nutrition, v. 140, n. 2, pp. 298-303, 2010.

[14] KHAGHANI, S., RAZI, F., YAJILOO, M. M., et al., "Selective cytotoxicity and apoptogenic activity of hibiscus sabdariffa aqueous extract against MCF-7 human breast cancer line", Journal of Cancer Therapy, 2, pp. 394-400, 2011.

[15] Builders, P. F., KABEle-TOGE, B., Chindo, B. A., et al., "Wound healing potential of formulated extract from hibiscus sabdariffa calyx", Indian Journal of Pharmaceutical Sciences, v. 75, n. 1, pp. 45-52, 2013.

[16] RAZALI, N., SALIT, M. S., JAWAID, M., et al., "A study on chemical composition, physical, tensile, morphological, and thermal properties of roselle fiber: effect of fiber maturity", Bioresources, v. 10, n. 1, pp. 1803-1824, 2015.

[17] CHAUHAN, A., KAITH, B., "Thermal and chemical studies of hibiscus sabdariffa-graft (vinyl monomers)", International Journal of Polymeric Materials and Polymeric Biomaterials, v. 60, n. 11, pp. 837-851, 2011.

[18] THOMAS, S., POTHAN, L. A., In: THOMAS, S., POTHAN, L. A. (eds). Natural fiber-reinforced polymer composites: From macro to nanoscale. Philadelphia: Old City Publishing Inc; 2008. 
[19] LI, X., TABIL, L. G., PANIGRAHI, S., "Chemical treatments on natural fiber for use in natural fiber reinforced composite: a review”, Journal of Polymer and the Environment, 15, pp. 25-33, 2007.

[20] FUQUA, M. A., HUO, S., ULVEN, C. A., "Natural fiber reinforced composites", Polymer Reviews, v. 52, n. 3, pp. 259-320, 2012.

[21] SAMPATHKUMAR, D., PUNYAMURTH, R., VENKATESHAPPA, S. C., et al., "Effect of chemical treatment on water absorption of areca fiber", Journal of Applied Science Research, v. 8, n. 11, pp. 5298$5305,2012$.

[22] SONIA, A., DASAN, K. P., "Chemical, morphology and thermal evaluation of cellulose microfibers obtained from hibiscus sabdariffa", Carbohydrate Polymers, v.92, pp. 668-674, 2013.

[23] THAMAE, T., BAILLIE, C., "Influence of fiber extraction method, alkali and silane treatment on Agave Americana waste HDPE composite as possible roof ceilings in Lesotho", Composite Interfaces, v. 14, n. (7-9), pp. 821-836, 2007.

[24] VILAY, V., MARIATTI, M., TAIB, R. M., et al., "Effect of fiber surface treatment and fibre loading on the properties of bagasse fiber-reinforced unsaturated polyester composites", Composite Science and Technology, v. 68, pp. 631-638, 2008.

[25] AZIZ, S. H., ANSELL, M. P., "The effect of alkalisation and fibre alignment on the mechanical and thermal properties of kenaf and hemp bast fiber composites: Part 1- polyester resin matrix", Composites Science and Technology, v. 64, pp. 1219-1230, 2004.

[26] DE ROSA, I. M., KENNY, J. M., PUGLIA, D., et al., "Morphological, thermal and mechanical characterisation of okra (abelmoschus esculentus) fibers as potential reinforcement in polymer composites", Composites Science and Technology, v. 70, pp. 116-122, 2010.

[27] SHOUHA, P., SWAIN, M., ELLAKWA, A., "The effect of fiber aspect ratio and volume loading on the flexural properties of flowable dental composite", Dental Materials, v. 30, pp. 1234-1244, 2014.

[28] GODA, K., CAO, Y., "Research and development of fully green composites reinforced with natural fibers”, Journal of Solid Mechanics and Materials Engineering, v. 1, n. 9, pp. 1073-1984, 2007.

[29] DELKUMBUREWATTE, G. B., "Properties and characteristics of fibers of roselle plant", Annual Academic Sessions, Open University of Sri Lanka, pp. 104-107, 2011.

[30] MODIBBO, U. U., ALIYU, B. A., NKAFAMIYA, I. I., "The effect of mercerisation media on the physical properties of local plant bast fibers”, International Journal of Physical Sciences, v. 4, n. 11, pp. 698-704, 2009.

[31] CELINO, A., FREOUR, S, JACQUEMIN, F., et al., "The hygroscopic behaviour of plant fibers: a review", Frontiers in Chemistry, v. 1, n. 43, pp. 1-12, 2014.

[32] AKIL, H. M., OMAR, M. F., MAZUKI, A. A. M., et al., "Kenaf fiber reinforced composites: a review”, Materials and Design, v. 32, n.8-9, pp. 4107-4121, 2011.

[33] MOHAN, T. P., KANNY, K., "Water barrier properties of nanoclay filled sisal fiber reinforced epoxy composites", Composites Part A: Applied Sciences and Manufacturing, v. 42, n. 4, pp. 385-393, 2011.

[34] KABIR, M. M., WANG, H., ARAVINTHAN, T., et al., "Effects of natural fiber surface composite properties: a review” Energy, Environment and Sustainability, eddBE2011 proceedings, pp. 94-99, 2011.

[35] GURUNATHAN, T., MOHANTY, S., NAYAK, S. K., A review of the recent developments in biocomposites based on natural fibers and their applications perspectives”, Composites: Part A, v. 77, pp. 1$25,2015$.

[36] FAO CORPORATE DOCUMENT REPOSITORY. "Application of natural fiber in the development of rural societies", Available: www.fao.org/dodrep/007/ad416e06.htm.

[37] DEEPA, B., ABRAHAM, E., CHERIAN, B. M., et al., "Structure, morphology and thermal characteristics of banana nano fibers obtained by steam explosion”, Bioresources Technology, v. 102, pp. 1988-1997, 2011.

[38] SHEHU, U., AUDU, H. I., NWAMARA, M. A., et al., "Natural fiber as reinforcement for polymers: a review”, South Pacific Journal of Technology and Science, v. 2, n. 1, pp. 238-253, 2014. 
[39] PAI, A. R., JAGTAP, R. N., "Surface morphology and mechanical properties of some unique natural fiber reinforced polymer composites - a review", Journal of Materials and Environmental Science, v. 6, n. 4, pp. 902- 917, 2015.

[40] SUMAILA, M., AMBER, I., BAWA, M., "Effect of fiber length on the physical and mechanical properties of random oriented, non-woven short banana (musa balbisiana) fiber/epoxy composite", Asian Journal of Natural and Applied Sciences, v. 2, n. 1, pp. 39-49, 2013.

[41] OBI, R. K., SHUKLA, M., UMA, M. C., et al., "Mechanical and physical characterisation of sodium hydroxide treated borassus fruit fibers", Journal of Forestry Research, v. 23, n. 4, pp. 667-674, 2012.

[42] BENYAHIA, A., MERROUCHE, A., ROKBI, M., et al., "Study the effect of alkali treatment of natural fibres on the mechanical behaviour of the composite unsaturated polyester-fiber alfa", In: $21^{\text {eme }}$ Congres Francais de Mecanique, Bordeaux, France, 26-30 August 2013.

[43] BEZAZI, A., BELAADI, A., BOURCHAK, M., et al., "Novel extraction techniques, chemical and mechanical characterisation of agave Americana L. natural fibers", Composites Part B: Engineering, 66, pp. 194-203, 2014.

[44] TELI, M. D., JADHAV, A. C., "Effect of alkali treatment on the properties of agave augustifolia v. marginata fiber", International Research Journal of Engineering and Technology, v. 3, n. 5, pp. 2754-2761, 2016.

[45] LIU, D., HAN, G., HUANG, J. H., et al., "Composition and structure study of natural nelumbo nucifera fiber, Carbohydrate Polymers, v. 75, n. 1, pp. 39-43, 2009.

[46] BALEY, C., BUSNEL, F., GROHENS Y., et al., "Influence of chemical treatments on surface properties and adhesion of flax fiber-polyester resin", Composites Part A: Applied Science and Manufacturing, 37, pp. 1626-1637, 2006.

[47] TELI, M. D., JADHAV, A. C., "Effect of alkalisation on the properties of abelmoschus manihot lignocellulosic fiber", International Journal of Current Engineering and Technology, v. 5, n. 6, pp. 3848$3855,2015$.

[48] SINGHA, A. S., THAKUR, V. K., "Mechanical properties of natural fiber reinforced polymer composites”, Bulletin of Materials Science, v. 31, n. 5, pp. 791-799, 2008.

[49] IQBAL, U., NAQASH, T., "Comparison of transverse strength and impact strength of high impact heat cure denture base resin with that of a conventional heat cure denture base reinforced with E-glass and polyethylene fibres: a research”, Medical Science, v. 15, n. 59, pp. 21-24, 2014.

[50] MURTHY, H. B. M., SHAIK, S., SACHDEVA, H., et al., "Effect of reinforcement using stainless steel mesh, glass fibre and polyethylene on the impact strength of heat cure denture base resin - an in vitro study", Journal of International Oral Health, v, 7, n. 6, pp. 71-79, 2015. 